\title{
Experimental Study of Gas Flow and Combustion in Biogas Generators
}

\author{
Yang Jianjun ${ }^{1 *}, 2$, Dong Dawei ${ }^{1}$, Yang Yanhong ${ }^{2,3}$, Meng Zhongwei ${ }^{3,4}$ and Hu Junming ${ }^{2,3}$ \\ ${ }^{1}$ School of Mechanical Engineering, Southwest Jiaotong University, Chengdu 610031, China \\ ${ }^{2}$ School of Automobile and Transportation, Xihua University, Chengdu 610039, China \\ ${ }^{3}$ Sichuan Collaborative Innovation Center for Automotive Key Components, Chengdu 610039, China \\ ${ }^{4}$ Key Laboratory of Fluid and Power Machinery, Ministry of Education, Chengdu 610039, China
}

Email: yangjj@mail.xhu.edu.cn

\begin{abstract}
Biogas is an environmentally friendly and clean, pollution-free fuel. In this paper, biogas generators have been researched in order to study the use of pig farm biogas in China. First, the pig farm biogas components are grouped, tested, and formulated. Since the biogas combustion process is not the same as for gasoline, biogas processing is carried out in a constant volume bomb combustion test, thus, the different components of biogas combustion speed, combustion pressure, and other information become available. The biogas combustion process in the combustion chamber and movement are simulated, and the cylinder pressure, speed, and temperature conditions are obtained. As can be seen from the experimental results, the biogas combustion speed is lower than that of gasoline, the ignition timing generator needs to be adjusted. In order to reduce the possibility of post-combustion occurring in the combustion chamber, certain combustion chamber swirl movements should be organized. The results show that by adjusting the ignition timing, air movement, and other factors, biogas can be used as fuel in generators.
\end{abstract}

Keywords: Biogas generator, Composition, Combustion, Cylinder pressure, Temperature, Motion.

\section{INTRODUCTION}

Biogas is a combustible gas which can be generated through the microbial fermentation of organic matter under anaerobic conditions [1]. It can be obtained by various methods. Biogas obtained by anaerobic fermentation of livestock manure is not only environmentally friendly, but also important for the rational use of energy [2]. In fact, biogas is a combustible gas with a high calorific value, and the calorific value is about $20-25 \mathrm{MJ} / \mathrm{m}^{3}$ [3-5]. Therefore, at the time of use, one cubic meter of biogas contains the equivalent of $0.8 \mathrm{~kg}$ calorific value of coal. Compared with other fuel, the biogas antiknock performance is better. Therefore, biogas is considered a good, clean fuel. Biogas is mainly composed of methane and carbon dioxide gas, and also contains a small amount of nitrogen, hydrogen, oxygen, and hydrogen sulfide, etc [6-8].

Biogas has been utilized for a long time. The use of largescale digester biogas power generation harbors good prospects for the effective use of biogas. As the fuel components of the biogas composition for conventional generators are not the same, it is necessary to analyze the biogas composition and study the methane flow in the combustion chamber and the combustion conditions [9-11]. For the study, a gasoline generator is converted into a biogas generator, as shown in Figure 1. The main structural parameters of a biogas generator are shown in Table 1.

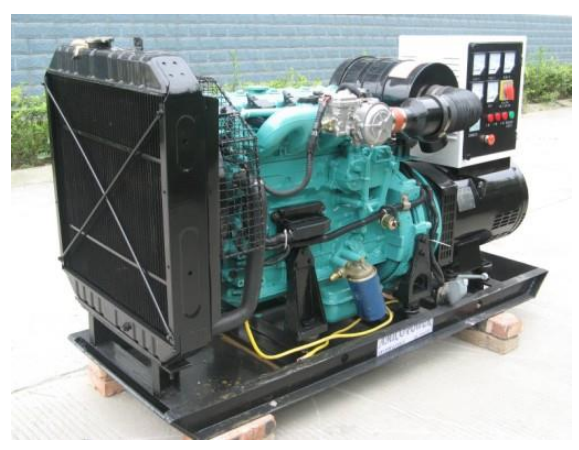

Figure 1. Biogas generator

Table 1. The main parameters of biogas generators

\begin{tabular}{ll}
\hline Item & Value \\
\hline Number of cylinders & 4 \\
Cylinder diameter $\times$ stroke & $102 \mathrm{~mm} \times 115 \mathrm{~mm}$ \\
Engine capacity & $3.76 \mathrm{~L}$ \\
Compression ratio & $12: 1$ \\
Nominal power/speed & $35 \mathrm{~kW} / 1500 \mathrm{r} / \mathrm{min}$ \\
Emission level & EPA T3 \\
\hline
\end{tabular}




\section{BIOGAS TEST}

\subsection{Biogas composition analysis}

Since the method of preparation or sources are not the same, the biogas composition will be different [12, 13]. Further, the proportion of methane in the case of the components will directly affect the biogas combustion process in the combustion chamber, thus affecting the output power of the generator $[14,15]$. Therefore, the composition of the pig farm biogas needs to be studied first. In the dry air temperature of $20{ }^{\circ} \mathrm{C}-25{ }^{\circ} \mathrm{C}$, relative humidity of $69 \%-73 \%$, atmospheric pressure of $94.6 \mathrm{kPa}-96.8 \mathrm{kPa}$, pig farm biogas components have been measured in three installments. A meteorological spectrograph is used to measure the composition of methane, and the results are shown in Table 2.

Table 2. Biogas composition

\begin{tabular}{lllll}
\hline & $\mathrm{N}_{2}$ & $\mathrm{CH}_{4}$ & $\mathrm{CO}_{2}$ & Other \\
\hline First group (\%) & 8.013 & 68.02 & 23.64 & 0.327 \\
Second group (\%) & 7.162 & 68.88 & 23.33 & 0.628 \\
Third group (\%) & 7.613 & 68.88 & 23.42 & 0.087 \\
Average (\%) & 7.6 & 68.6 & 23.46 & 0.34 \\
\hline
\end{tabular}

Based on the above experimental results, the pig farm biogas in the standard state of low calorific value is 24.625 $\mathrm{MJ} / \mathrm{Nm}^{3}$, the corresponding density of the gas methane is $1.052 \mathrm{~kg} / \mathrm{Nm}^{3}$.

\subsection{Biogas combustion velocity test}

A biogas generator is a typical internal combustion engine. A premixed laminar flame is the basis of the premixed turbulent combustion model, which provides a detailed chemical reaction that occurs during combustion research dynamics [16-18]. It is also an important means to clarify the combustion mechanism.

The main components of biogas are methane and carbon dioxide $[10,19]$. Research shows that methane's combustion speed is slightly slower than that of some of the gasolines, which is about $37.3 \mathrm{~cm} / \mathrm{s}$. At the same time, carbon dioxide has little inhibitory effect on combustion. Therefore, the biogas combustion speed is slower than that of methane [20]. Biogas fuel burns slowly, resulting in the biogas combustion engine's combustion duration becoming longer, reducing the combustion efficiency, serious post-combustion, a rise in exhaust temperature, reliability, and a deterioration in engine economy, and the like [21, 22]. Therefore, the biogas premixed laminar flame and combustion characteristics in this study can provide a theoretical basis for the development of control strategies for biogas engines.

In order to study the effect of carbon dioxide gas on the combustion of methane gas, an experiment on the combustion rate of mixes with different proportions was carried out. The test equipment is mainly composed of a constant volume combustion bomb, a light path system, an air distribution system, an ignition system, a data acquisition system, and a high-speed camera system, as shown in Figure 2.

A mixture of methane and carbon dioxide was used as the research object. The experimental study was carried out in a constant volume combustion bomb, and compared with pure methane, the laminar burning characteristics of biogas were obtained. The combustion speed is the movement speed of the reaction zone corresponding to the non-combustible gas mixture $[23,24]$. The burning rate of pure $\mathrm{CH}_{4}$ and the mixed gas of $70 \% \mathrm{CH}_{4}$ and $30 \% \mathrm{CO}_{2}$ were measured respectively in the experiment, and the test results are shown in Figure 3.

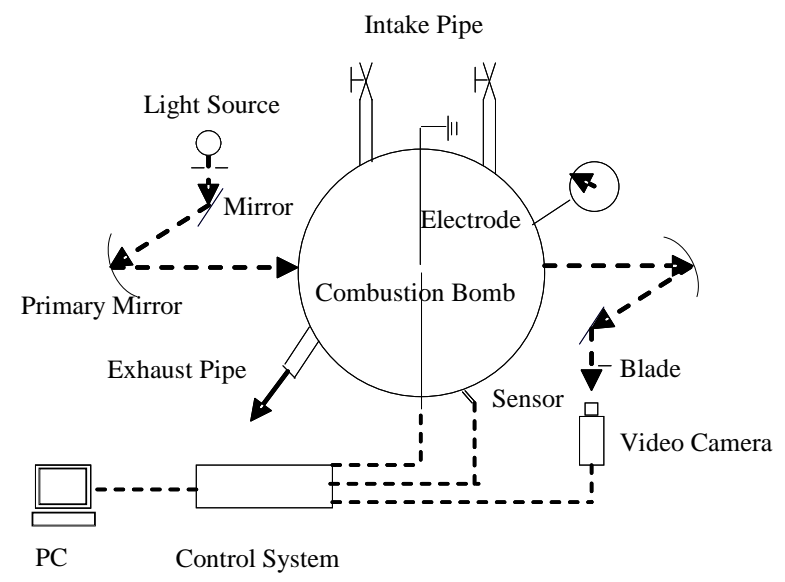

Figure 2. Schematic diagram of experimental device

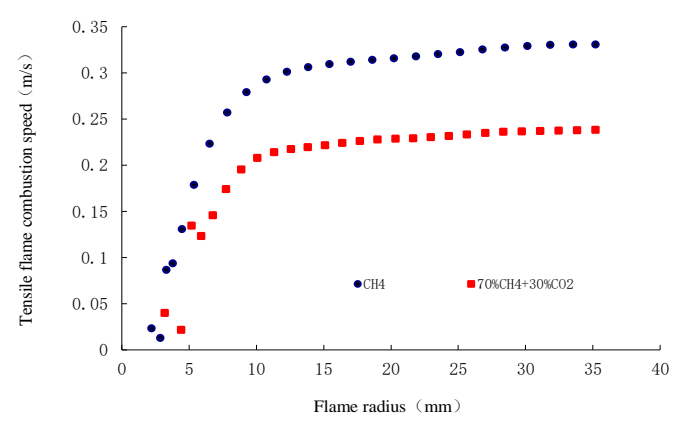

Figure 3. Results of tensile flame combustion speed

As can be seen from the figure, the burning rate of the two gases has the same change trend. In the early stage of flame propagation, the burning velocity is small. With an increase of the flame radius, the combustion speed in the flame radius between 5 and $10 \mathrm{~mm}$ increases rapidly. Especially after 10 $\mathrm{mm}$ with the radius increasing, the combustion speed change rate decreases and the numerical tends to a constant value. It can be seen that once the flame radius is greater than $5 \mathrm{~mm}$, the burning rate of pure $\mathrm{CH}_{4}$ is higher than $70 \%$ of the $\mathrm{CH}_{4}$ and $30 \%$ of the $\mathrm{CO}_{2}$ mixture. This is because the $\mathrm{CO}_{2}$ in the mixed gas has a strong inhibitory effect on combustion, so the burning rate of biogas has become slow.

\subsection{Biogas combustion pressure test}

During the combustion process, the maximum combustion pressure comes sooner or later, which has a significant impact on the performance of the internal combustion engine [17, 22]. Experimental measurements were also carried out on the combustion pressure of $\mathrm{CH}_{4}$ and $70 \%$ of $\mathrm{CH}_{4}$ and $30 \%$ of $\mathrm{CO}_{2}$ mixture using experimental equipment. The experimental results are shown in Figure 4. 


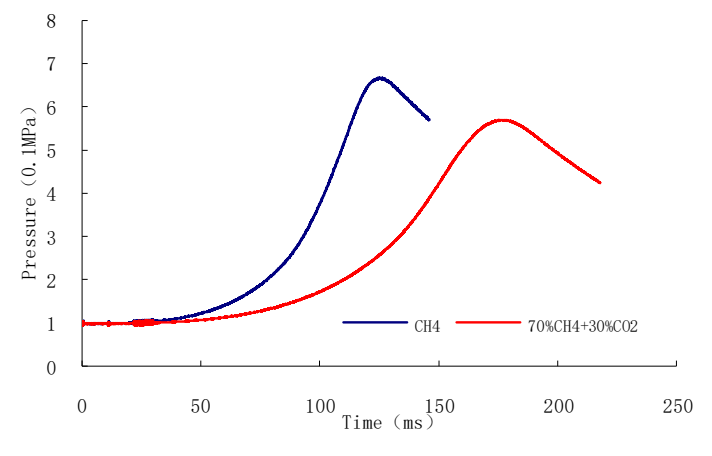

Figure 4. Measured pressure diagram

The figure shows that pure $\mathrm{CH}_{4}$ combustion is faster, and the pressure rise rate is greater. With a burning time of 125 ms, pure methane combustion reaches the maximum combustion pressure $0.67 \mathrm{Mpa}$. Due to the addition of $\mathrm{CO}_{2}$, the mixed gas combustion speed becomes slow, the highest pressure is prolonged, and the maximum pressure is also reduced. At $175 \mathrm{~ms}$ time, the combustion gas mixture reaches a peak pressure of $0.57 \mathrm{Mpa}$. Therefore, as $\mathrm{CO}_{2}$ is added to the combustion of the mixture in the entire combustion process time required for growth, the combustion rate of $\mathrm{CO}_{2}$ inhibition becomes more obvious. Due to the high $\mathrm{CO}_{2}$ content in biogas, the combustion is strongly inhibited. So that the combustion pressure has time to reach the highest growth, the entire combustion process is extended. Thus, with respect to the methane combustion engine, it must be adjusted according to changes in its composition of air-fuel ratio and ignition timing, and appropriate control strategies to improve the economy and power need to be developed. So, studying biogas combustion gases is crucial.

\section{BIOGAS COMBUSTION SIMULATION}

\subsection{Combustion model}

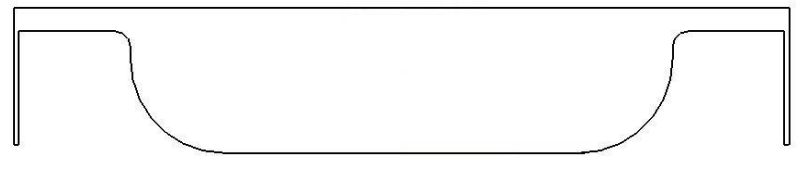

Figure 5. Schematic diagram of the combustion chamber

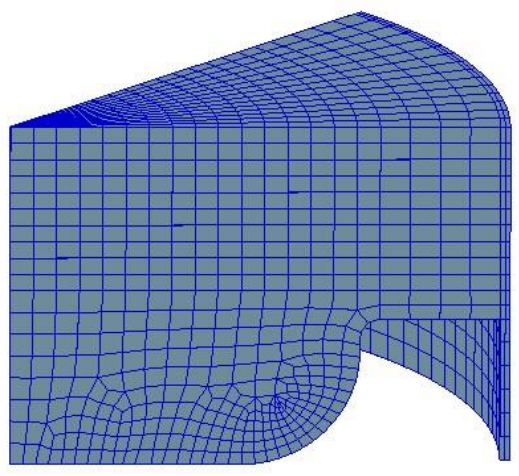

Figure 6. $320^{\circ} \mathrm{CA}$
Compared with the laminar flame propagation velocity of gasoline, biogas is more slow. Thus, through the organization of in-cylinder combustion, the air movement to facilitate the conduction of spark-ignition internal combustion gas becomes particularly important $[8,15,23]$. In order to analyze the influence of a shallow bowl-shaped cylinder chamber on the combustion of mixed gas, a gas generator combustion was numerically simulated. Since the center of the combustion chamber is symmetrical, to save time, 1/8 of the volume of the combustion chamber space is studied. Figure 6 is $1 / 8$ the volume's grid graph of the biogas generator combustion chamber at $320^{\circ} \mathrm{CA}$.

Calculation is set to start from the $228^{\circ} \mathrm{CA}$ (intake valve closed) to $484^{\circ} \mathrm{CA}$ end (exhaust valve opening). The computing speed is set to $1500 \mathrm{r} / \mathrm{min}$, and the spark advance angle is $27^{\circ} \mathrm{CA}$ BTDC. Biogas components are set in accordance with the experimental results in Table 2 . In the calculation, the standard $\kappa-\varepsilon$ two-equation model is adopted as the origins of the gas flow model, and the spark ignition model is set to the ignition model. The biogas combustion is set to CFM-2A continuous flame model, $\mathrm{NO}_{\mathrm{X}}$ is generated using the Zeldovich model, and the KennedyHiroyasu-Magnussen model is set to the soot generation model. Boundary conditions are set as shown in Table 3.

Table 3. Boundary conditions

\begin{tabular}{ll}
\hline Position & Temperature $(\mathrm{K})$ \\
\hline The cylinder head wall & 520 \\
Cylinder & 475 \\
Piston surface & 550 \\
Fuel & 320 \\
\hline
\end{tabular}

\subsection{Cylinder pressure}

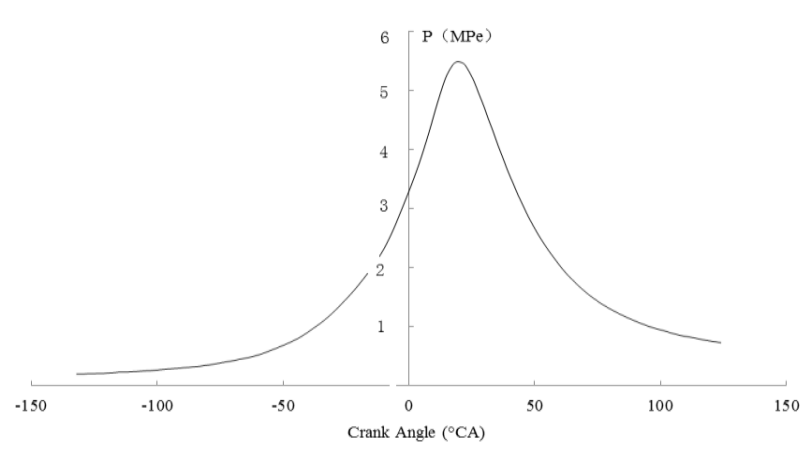

Figure 7. Cylinder pressure graph

Figure 7 is a graph of cylinder pressure biogas generators of 4102 obtained by calculation. The internal combustion engine fuel is biogas, therefore, the flame propagation velocity of the mixture is slow. This has resulted in the burning rate of the combustible mixture slowing down, thus, the ignition timing is adjusted to $27^{\circ}$ CA BTDC. By simulation, it can be seen that the mixture is ignited at $336^{\circ}$ CA (-27 ${ }^{\circ} \mathrm{CA}$ BTDC), and the maximum value of the combustion pressure appears at $380^{\circ} \mathrm{CA}\left(20^{\circ} \mathrm{CA}\right.$ ATDC). This is because the gas burns slowly, and the maximum instantaneous rate of heat release needs to be reached over a long time. With post-combustion, combustion continues until $430^{\circ} \mathrm{CA}\left(70^{\circ} \mathrm{CA}\right.$ ATDC) and is basically about to be completed. 


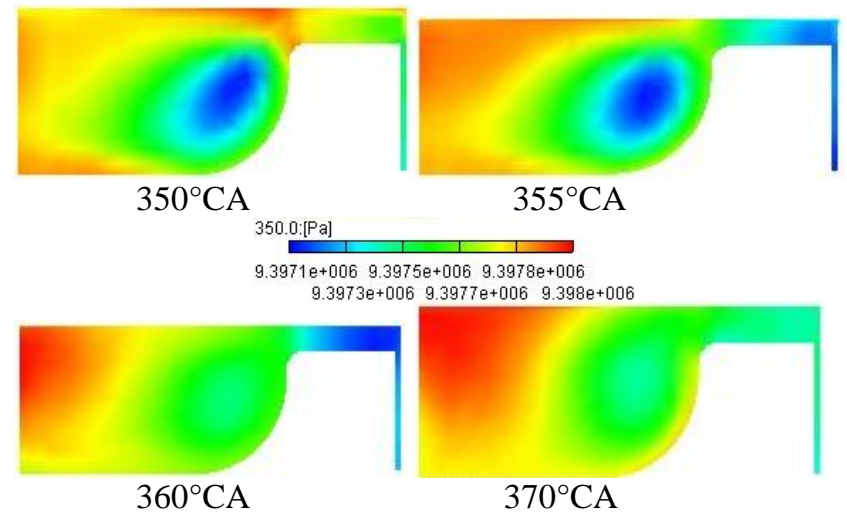

Figure 8. Cylinder pressure

Figure 8 shows the pressure in the cylinder at different times in the combustion chamber. The pressure in the combustion chamber gradually changes with the operation of the crankshaft. In the vicinity of the TDC, the highest pressure occurs near the center of the combustion chamber, which is advantageous for improving the dynamics of the engine. Compared with the combustion chamber center, the pressure in the combustion chamber pit is lower. It is presumed that the swirling motion in this area is strong, and a negative pressure zone is formed, leading to a decrease in pressure.

\subsection{Combustion temperature}

Figure 9 shows the temperature profile of the generator at different times when biogas is used as the fuel. The spark plug is ignited at $24^{\circ} \mathrm{CA}$ BTDC, and it can be seen that even at $350^{\circ} \mathrm{CA}$, the highest temperature region in the cylinder is only concentrated in a smaller region near the spark plug. The temperature appears as surrounding radiation, and the vast majority of the combustion chamber of the cylinder has a low temperature. This is mainly because the activation energy of biogas is high, which leads to the slow propagation of the flame, and the combustion cannot be fully developed in the whole combustion chamber space in a short time. With the further development of the combustion process, the hightemperature region in the combustion chamber gradually spreads from the vicinity of the spark plug to the cavity and around the combustion chamber. During the whole combustion process, the region near the spark plugs becomes a high-temperature region.
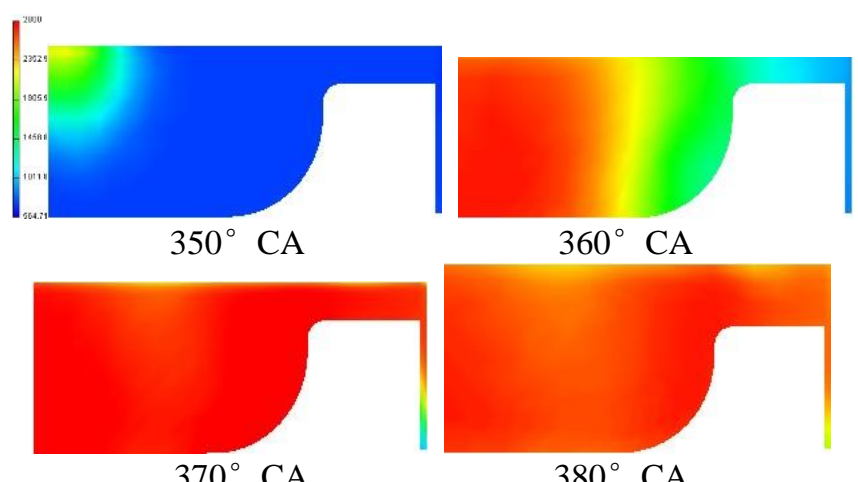

Figure 9. Cylinder temperature

\subsection{Cylinder mixture motion}

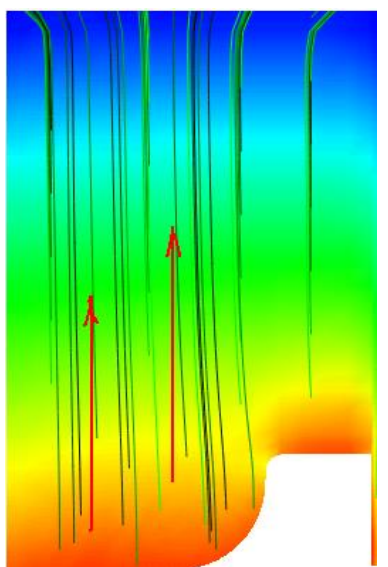

$280^{\circ} \mathrm{CA}$

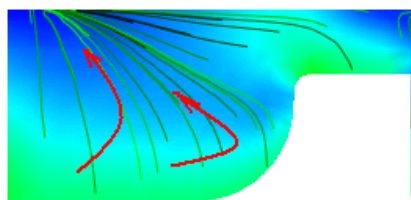

$340^{\circ} \mathrm{CA}$

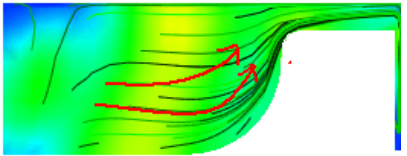

$355^{\circ} \mathrm{CA}$

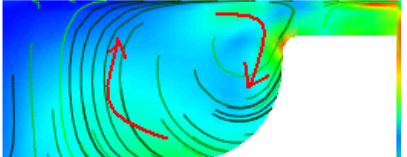

$370^{\circ} \mathrm{CA}$

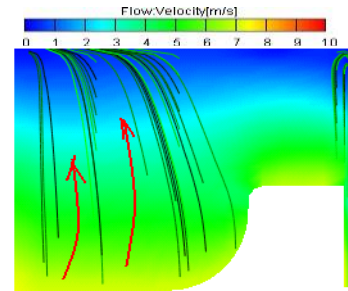

$320^{\circ} \mathrm{CA}$

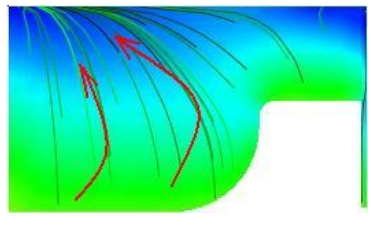

$330^{\circ} \mathrm{CA}$

$350^{\circ} \mathrm{CA}$

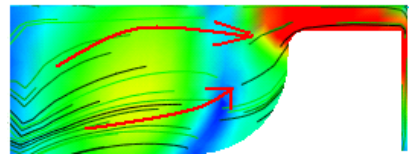

$360^{\circ} \mathrm{CA}$

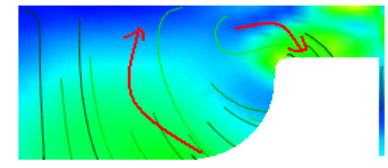

$380^{\circ} \mathrm{CA}$

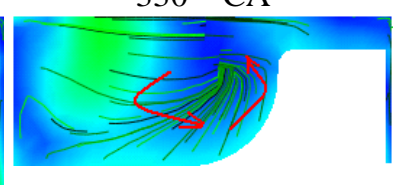

Figure 10. Cylinder mixture motion

Excellent combustion chamber design can reasonably guide the flow of gas mixture in the cylinder, so that the gas is completely burned to improve the output performance of the internal combustion engine. Therefore, the study of gas flow in the cylinder is very important. Figure 10 shows the velocity field of the mixture in the cylinder of the internal combustion engine at different times.

As can be seen from the figure, before $320^{\circ} \mathrm{CA}$, the direction of movement of the cylinder gas mixture is from bottom to top. In addition to the combustion chamber pit portion, the vast majority of the mixed gas space velocity is low. Moreover, almost no swirling motion is generated. This is because of the unique design of the shallow bowl-shaped combustion chamber, which can produce a small vortex.

When the compression process continues at between $320^{\circ}$ $\mathrm{CA}$ to $340^{\circ} \mathrm{CA}$, a weak vortex with counterclockwise movement is gradually formed, which is mainly produced in the pit portion of the combustion chamber. At this stage, the main direction of the cylinder air movement is from the bottom to the top, and the high-speed area is located at the bottom of the combustion chamber and the position of the backlash. Starting from $350^{\circ} \mathrm{CA}$, in the area above the pit portion of the combustion chamber a swirling motion in counterclockwise direction gradually forms. The center position speed of the vortex region is not high, compared with the velocity of the center of the combustion chamber. The high-speed motor area of the combustion chamber portion of the pit gradually shifts to the side, which is a major cause of 
the indoor combustion vortex formation. As the intensity of the vortex compression process increases, it is near the TDC peak. During the compression process, the vortex strength increases, and reaches its maximum in the vicinity of the TDC. After that, as the piston comes down, the counterclockwise swirling motion turns clockwise. The vortex center gradually shifts from the position of the combustion chamber to the backlash surrounding the pit portion. The intensity of the swirling motion gradually weakens, which shows a substantially opposite process to the compression process of the air movement.

If the shallow basin-shaped combustion chamber is not organized, there is a violent movement caused by cylinder turbulence. Compared with gasoline, biogas combustion is slow. The shallow bowl-shaped swirl chamber formed in the vicinity of the TDC becomes larger, which increases the flame propagation speed and speeds up the combustion process. Clearly, the swirling motion of the cylinder strength is weak, and only slightly stronger in the vicinity of the TDC. Overall, due to the design of the shallow basin-shaped combustion chamber, the strength generated by its swirling motion is small.However, due to the high activation energy and slow biogas combustion, the swirling motion in the shallow bowl-shaped combustion chamber produces a smaller initial ignition that will contribute to the formation of a stable flame center. In order to avoid too large a swirling motion from influencing the formation of a spark plug, the ignition and flame center need to be reliable. In order to optimize the combustion process and improve the performance of the internal combustion engine, a reasonable exercise to boost the development of in-cylinder gas flow velocity needs to be conducted, thereby speeding up the process of combustion, and the performance of the internal combustion engine needs to be further improved, taking into account the generator produces a certain degree of post-combustion.

\section{CONCLUSIONS}

Biogas ingredients are conducive to clean combustion, and can be obtained by a variety of ways. China's biogas contains an abundant amount and can be reasonably utilized. The use of biogas to generate electricity is pig farm biogas recycling, which has high economic and social value. To study the internal combustion engine's biogas utilization, a gasoline generator is converted into a biogas generator. Due to differences in gas composition, gas compositions from pig farms were tested to obtain a reasonable composition of biogas. Taking into account the different components of gasoline and methane, biogas combustions of different compositions were measured within a constant volume bomb. The cylinder pressure and combustion speed of biogas were thus obtained. On this basis, the generator combustion gas motion is simulated to obtain gas movement speed, pressure, and temperature conditions. The results show that by adjusting the ignition timing, compression ratio, and other factors and replacing the combustion chamber, biogas can be effectively utilized in a generator.

\section{ACKNOWLEDGMENTS}

This work was supported by (1) The National Natural Science Foundation of China (51106130); (2) The Chunhui Plan of the Ministry of Education of China (Z2014058); (3) The industry cluster project for electronic engine control systems and after treatment systems of Chengdu, China ([2013] 265); (4) New energy vehicle electronic control technology in Sichuan province Youth Science and Technology Innovation Research Team (2015TD0021); (5) The open research subject of Key Laboratory of Fluid and Power Machinery (Xihua University), Ministry of Education (szjj2016 - 005).

\section{REFERENCES}

[1] Liu, N., Zheng, Z. and Li, G., "Analysis of diesel engine main bearing lubrication under single-cylinder misfiring situation," Int J Heat \& Tech, vol. 33, no. 4, pp. 85-90, 2015. DOI: 10.18280/ijht.330411.

[2] Sarma, P. K., Krishna, D. Radha and Ramanarayanan, C. P., "Analysis of engine oil cooler of an unmanned aeroengine at various altitudes," Int J Heat \& Tech, vol. 30, no. 1, pp. 45-50, 2012.

[3] Arapatsakos, Charalampos, Karkanis, Anastasios and Anastasiadou, Christina, "The load and the gas emissions measurement of outboard engine," Int $J$ Heat \& Tech, vol. 33, no. 4, pp. 221-228, 2015. DOI: 10.18280/ijht.330430.

[4] Matsakas, Leonidas1, Rova, Ulrika and Christakopoulos, Paul, "Strategies for enhanced biogas generation through anaerobic digestion of forest material-An overview," BioResour, vol. 11, no. 2, pp. 5482-5499, 2016.2 DOI: 10.15376/biores.11.2.Matsakas.

[5] Li, S., Zhang, Y.D., Li, Y. and Liao, R.Q., "Equilibrium calculation and technological parameters optimization of natural gas liquefaction process with mixed refrigerant," Int. J. Heat Technol., vol. 33, no. 2, pp. 123-128, 2015. DOI: 10.18280/ijht.330220.

[6] Yang Jianjun, Dong Dawei, Meng Zhongwei, Yang Yanhong and Wang Yi , "different types of flow field and engine performance of the vortex throttle," Int. $J$. Heat Technol., vol. 34, no. 2, pp. 319-324, 2016. DOI: 10.18280/ijht.340223.

[7] Chen, Lei, Mikiya, Araki, Seiichi, Shiga and Zeng, Wen, "Combustion and emission characteristics of individual component of biogas in SI engine," Nongye Jixie Xuebao, vol. 44, no. 5, pp. 31-34, 2013. DOI:10.6041/j.issn.1000-1298.2013.05.006.

[8] Holly, Werner E., Lauer, Thomas, Schuemie, Henrik A. and Murakami, Shinsuke, "Prediction of the knocking combustion and NOx formation for fuel gases with different methane numbers," Int. J. Engine Res, vol. 17, no. 1, pp. 35-43, 2016. DOI: 10.1177/1468087415594952.

[9] Park, Su Han, Yoon and Seung Hyun, "Effect of dualfuel combustion strategies on combustion and emission characteristics in reactivity controlled compression ignition (RCCI) engine," Fuel, vol. 181, pp. 310-318, 2016. DOI: $10.1016 /$ j.fuel.2016.04.118.

[10] Arapatsakos, Charalampos, "The influence of natural gas in a four-stroke engine," Int. J. Heat Technol., vol. 29, no. 2, pp. 119-125, 2011.

[11] Kwon, Soon Tae, Park, Chanjun and Ohm, Inyong, "Combustion characteristics of landfill gas in constant volume combustion chamber for large displacement volume engine (II) -Combustion analysis," Trans. Korean Soc. Mech. Eng., vol. 37, no. 8, pp. 743-752, 2013. DOI: $10.3795 /$ KSME-B.2013.37.8.743. 
[12] Effuggi, Alessandro, Gelosa, Davino, Derudi, Marco and Rota, Renato, "Mild combustion of methanederived fuel mixtures: Natural gas and biogas," Combust Sci Technol, vol. 180, no. 3, pp. 481-493, 2008. DOI: $10.1080 / 00102200701741368$.

[13] Hosseini, Seyed Ehsan, Bagheri, Ghobad and Wahid, Mazlan Abdul, "Numerical investigation of biogas flameless combustion," Energy Convers. Manage., vol. 81, pp. 41-50, 2014. DOI: 10.1016/j.enconman.2014.02.006.

[14] Musmar, Sa'Ed A. and Al-Kanhal, Tawfeeq, "Design optimization of thermal heat engines," Int. J. Heat Technol., vol. 32, no. 1-2, pp. 45-50, 2014.

[15] Hosseini, Seyed Ehsan, Wahid and Mazlan Abdul, "Biogas utilization: Experimental investigation on biogas flameless combustion in lab-scale furnace," Energy Convers. Manage., vol. 74, pp. 426-432, 2013. DOI: $10.1016 /$ j.enconman.2013.06.026.

[16] Colorado, A.F., Herrera, B.A. and Amell, A.A., "Performance of a Flameless combustion furnace using biogas and natural gas," Bioresour. Technol., vol. 101, no. 7, pp. 2443-2449, 2010. DOI: 10.1016/j.biortech.2009.11.003.

[17] Cacho, Juan, Oliveros, Alfredo and Barrera, Jhordann, "Development of a biogas fuel supply system for an internal combustion engine," Distrib. Gener. Altern. Energy J., vol. 26, no. 3, pp. 6-19, 2011. DOI: 10.1080/21563306.2011.10462195.

[18] Ramesha, D.K., Bangari, Adhiviraj Singh, Rathod, Chirag P. and Samartha Chaitanya, R., "Combustion, performance and emissions characteristics of a biogas fuelled diesel engine with fish biodiesel as pilot fuel," Biofuels, vol. 6, no. 1-2, pp. 9-19, 2015. DOI: $\underline{10.1080 / 17597269.2015 .1036960 .}$.

[19] Arroyo, J., Moreno, F., Muñoz, M., Monné, C. and Bernal, N., "Combustion behavior of a spark ignition engine fueled with synthetic gases derived from biogas," fuel, vol. 117, no. PART A, pp. 50-58, 2014. DOI: 10.1016/j.fuel.2013.09.055.

[20] Khaleghi, Mostafa, Hosseini, Seyed Ehsan and Wahid, M.A., "Experimental and numerical investigations of biogas vortex combustion," Proc. Inst. Mech. Eng. Part A J. Power Eng., vol. 229, no. 6, pp. 662-676, 2015. DOI: $10.1177 / 0957650915584717$.

[21] Bedoya, Iván D., Saxena, Samveg, Cadavid, Francisco J., Dibble and Robert W., "Numerical analysis of biogas composition effects on combustion parameters and emissions in biogas fueled HCCI engines for power generation," J. Eng. Gas Turbines Power, vol. 135, no. 7, pp. 1412-1438, 2013. DOI: 10.1115/1.4023612.

[22] Charest, Marc R.J., Gülder, O“mer L., Groth and Clinton P.T., "Numerical and experimental study of soot formation in laminar diffusion flames burning simulated biogas fuels at elevated pressures," Combust. Flame, vol. 161, no. 10, pp. 2678-2691, 2014. DOI: 10.1016/j.combustflame.2014.04.012.

[23] Bedoya, Iván D., Saxena, Samveg, Cadavid, Francisco J., Dibble, Robert W. and Wissink, Martin, "Experimental evaluation of strategies to increase the operating range of a biogas-fueled HCCI engine for power generation," Appl. Energy, vol. 97, pp. 618629, 2012. DOI: $10.1016 /$ j.apenergy.2012.01.008.

[24] Karellas, Sotirios, Boukis, Ioannis and Kontopoulos, Georgios, "Development of an investment decision tool for biogas production from agricultural waste," Renew Sustain Energy Rev, vol. 14, no. 4, pp. 1273 1282, 2010. DOI: $10.1016 /$ j.rser.2009.12.002.

\section{NOMENCLATURE}

$\begin{array}{ll}\text { CA } & \text { Crank angle } \\ \text { TDC } & \text { Top dead center } \\ \text { ATDC } & \text { After top dead center } \\ \text { BTDC } & \text { Before top dead center }\end{array}$

